\title{
Dermatología del viajero
}

\section{Traveler's dermatology}

Hay quienes viajan por placer como turistas, están aquellos que emigran por necesidad y destaco a los viajeros que desean cambiar su paradigma, expandir su visión del mundo y enfrentar nuevos retos. Los movimientos en masa representan una característica de los seres humanos, en busca de establecerse en un área geográfica favorable y de mejorar su calidad de vida. Sin embargo, la necesidad del hombre de adaptarse a situaciones climáticas adversas, los desastres medioambientales, las guerras y el hambre gestaron éxodos masivos, como en la posguerra, con la migración de europeos hacia América, el movimiento latinoamericano a finales del siglo pasado y principios de este, y también de inmigrantes de países africanos y de Oriente Medio a Europa en los últimos años.

Como viajante y médico dermatólogo, migrar me abrió un sinfín de nuevos desafíos. Uno de los aspectos que modifiqué de mi conducta en África fue comprender el contexto sociocultural de las dermatosis. Entendí, desde una postura empática, el efecto social de ciertas dermatosis, hasta entonces inocuo desde mi visión, como en el caso del vitiligo en los fototipos altos y cómo ello repercute en la calidad de vida y en la aceptación por los demás, sin dejar de lado la importancia de los peinados ajustados en las mujeres africanas y las consecuencias que acarrea para su cuero cabelludo. Migrando luego al Viejo Continente, vivencié el proceso de la inserción social de los inmigrantes de países en conflicto armado, que importaron dermatosis como la escabiosis y desataron brotes casi incontrolables $y$, probablemente, resistentes a la permetrina, con la consiguiente necesidad de aprobar el uso de la ivermectina oral en Europa, hasta entonces solo utilizada para fines veterinarios.

Durante mi vida como viajero en los últimos cinco años, tuve el placer de pertenecer al Comité de redacción de Dermatología Argentina. Pertenecer, aun a la distancia, viajar y establecer lazos con colegas de todo el mundo, me facilitó entender el concepto de médico pionero. Ser pionero no solo significa publicar artículos en revistas de alto impacto o utilizar los medicamentos biológicos de última generación, sino atreverse a salir de la zona de confort, emprender un rumbo desconocido y conectarse, así, con el mundo desde las propias vivencias. Viajar, como método de aprendizaje, permite grabar cada una de estas experiencias de forma inimitable en el libro de la vida.

David A. De Luca Médico Especialista en Dermatología Bad Neustadt (Saale), Alemania 